\title{
Psychometric Properties of the Korean Version of the Overactive Bladder Questionnaire (OAB-q) in a Korean Population
}

\author{
Seung-June Oh, Hwancheol Son ${ }^{1}$, Soo Wong Kim, Kyu-Sung Lee, Myung-Soo Choo ${ }^{3}$, Seon-Ok Kim${ }^{4}$, Moo Song Lee ${ }^{4}$ \\ Department of Urology, Seoul National University Hospital, Seoul; \\ ${ }^{1}$ Department of Urology, SMG-SNU Boramae Medical Center, Seoul; \\ ${ }^{2}$ Department of Urology, Samsung Medical Center, Seoul; \\ Departments of ${ }^{3}$ Urology and ${ }^{4}$ Clinical Epidemiology and Biostatistics, Asan Medical Center, Seoul, Korea
}

\begin{abstract}
Purpose: Psychometric properties of the overactive bladder questionnaire (OAB-q) were recently examined. However, since the cross-cultural adaptation of a non-English version of the OAB-q has never been demonstrated, we evaluated the psychometric properties of a Korean version of the OAB-q in a Korean population with OAB.

Methods: A prospective cohort study involving 116 women with $58 \mathrm{OAB}$ and 58 control subjects was performed and convergent validity was assessed. Total and subscale $\mathrm{OAB}-\mathrm{q}$ scores of the control and $\mathrm{OAB}$ groups were compared to their sensitivity to score changes before and after administering anti-cholinergic medication for 12 weeks. Short form 36 and King's health questionnaire (KHQ) were also used for comparison or correlation.

Results: Assessment of face validity showed that the Korean version of the OAB-q was reasonable with OAB-q subscale scores being significantly different between the control and patient groups. Significant correlation (range, -0.29 to -0.81 ) was found between the OAB-q scores and KHQ results for the OAB patients. Cronbach's alpha coefficients (range, 0.77 to 0.95 ) indicated excellent internal consistency and test-retest analysis involving $35 \mathrm{OAB}$ patients showed that each questions as well as subscale scores were reproducible. Each score of OAB-q also showed statistically significant sensitivity to changes following anti-muscarinic treatment for $\mathrm{OAB}(\mathrm{n}=27, \mathrm{P}<0.001$ except for social, $\mathrm{P}=0.059)$.

Conclusions: The Korean version of the OAB-q is a valid and reliable instrument to measure outcomes in Korean patients with OAB.
\end{abstract}

Keywords: Overactive urinary bladder; Quality of life; Questionnaires; Psychometrics

\section{INTRODUCTION}

Overactive bladder $(\mathrm{OAB})$ is characterized by symptoms of urinary urgency which may be accompanied by urge incontinence, increased urination frequency, and/or nocturia [1]. The overall prevalence of chronic and debilitating $\mathrm{OAB}$ symptoms in six European countries is $16.6 \%$ [2]. In the United States (US), the prevalence of $\mathrm{OAB}$ is very similar to that in Europe, with $16.0 \%$ in men and $16.9 \%$ in women suffering from this condition [3]. The estimated total economic cost of $\mathrm{OAB}$ is over 12 billion dollars in 2000 in the US alone [4].
$\mathrm{OAB}$ has been shown to cause significant symptom burden and impairs health-related quality of life (HRQoL) by interfering with daily activities, travel, sleep, and personal relationships [5-8]. Among the many questionnaires available for evaluating lower urinary symptoms, the King's health questionnaire (KHQ) $[9,10]$, OAB questionnaire (OAB-q) $[7,11,12]$ and OAB symptom score $[13,14]$ have been validated for clinical use in a sample of incontinent $\mathrm{OAB}$ patients. The $\mathrm{OAB}-\mathrm{q}$ was developed by Coyne et al. [7] in the US. It consists of 33 self-administered questions, eight which involve a symptom-bother scale and 25 involving HRQoL scores that constitute four subscales measur-
Corresponding author: Seung-June Oh

Department of Urology, Seoul National University Hospital, 101 Daehak-ro, Jongno-gu, Seoul 110-744, Korea

Tel: +82-2-2072-2406 / Fax: +82-2-742-4665 / E-mail: sjo@snu.ac.kr

Submitted: May 4, 2012 / Accepted after revision: June 20, 2012
This is an Open Access article distributed under the terms of the Creative Commons Attribution Non-Commercial License (http://creativecommons.org/licenses/by-nc/3.0/) which permits unrestricted non-commercial use, distribution, and reproduction in any medium, provided the original work is properly cited. 
ing coping, concern, sleep, and social interaction. The OAB-q questions are simple and easy to answer. Two subset of the OAB-q, the OAB-q short form (SF) and screening tool (OAB-q $\mathrm{V} 8$ ), were derived from the original OAB-q. The OAB-q SF was developed by selecting six items from the original eight symptom-bother items and 13 items from the original $25 \mathrm{HRQoL}$ items. The OAB-q V8 consists of the first eight OAB-q questions. Patients rate each item using a six-point Likert scale ranging from 'none of the time' to 'all of the time' for the HRQoL items and 'not at all' to 'a very great deal' for the symptom-bother items. Therefore, higher symptom severity score values are indicative of greater symptom severity or bother, whereas higher HRQoL scores are indicative of better HRQoL [7]. Subscale responses are summed and converted into scores ranging from 0 to 100 .

Evaluation of the psychometric properties was performed and demonstrated that the concurrent validity and discriminant validity [7], test-retest [11], and responsiveness [12] of the US English version of the OAB-q are acceptable. This questionnaire was translated into 14 different languages including French, German, Italian, Danish, and Korean [15]. To use the translated questionnaire in clinical practice as well as for clinical research, the psychometric properties of the translated versions should be accurately validated. Full validation and cross-cultural adaptation of the non-English version of the OAB-q has been performed in Danish, German, Polish, Swedish, and Turkish [16]. The primary objective of this study was to investigate whether the Korean version of the OAB-q provides valid and reliable information on Korean patients with OAB.

\section{MATERIALS AND METHODS}

This study was a prospective multi-center cohort study involving Seoul National University Hospital (SNUH) and SMG-SNU Boramae Medical Center (Seoul, Korea) which is an affiliated of SNUH. Participants were recruited from individual urology clinics and the study protocol was approved by the Institutional Review Boards of SNUH (H-0610-035-187).

Patients willing to participate in the study were recruited based on specific criteria with the definition of $O A B$ used in this study followed the recent standardized terminology of the International Continence Society [1]. The diagnosis of $\mathrm{OAB}$ was based primarily on the investigators' assessment of the participant's history during the first visit. Inclusion criteria were: 1) $\mathrm{OAB}$ symptoms for at least 6 months, 2) ages greater than 18 years old, 3) not currently taking medication for OAB symptoms, 4) not pregnant or nursing, and 5) absence of an acute urinary tract infection. Exclusion criteria were: 1) predominant stress urinary incontinence, 2) an indwelling catheter or intermittent catheterization, 3) symptoms of or recurrent urinary tract infection, 4) bladder cancer, 5) hepatic or renal dysfunction, 6) diabetic neuropathy, 7) congenital urological disorders, 8) undergoing electrostimulation, bladder training, or pelvic floor exercise within 4 weeks of study entry, and 9) pregnancy. Individuals who were less than 18 years old or who do not read and write were also excluded. Overall, 58 patients were enrolled in the $\mathrm{OAB}$ group. To assess the OAB-q responsiveness, a total of 35 out of $58 \mathrm{OAB}$ patients were given anticholinergic medication for 3 months. A total of 104 women with each group sample sizes of 52 was needed to achieve $80 \%$ power detecting a difference of 11.0 between the two groups with known group standard deviations of 20.0 and with a significance level (alpha) of 0.05 . Therefore, a total of 116 women with 58 subjects in each group were enrolled, considering follow-up loss rate of $15 \%$. A total of 35 subjects were enrolled for test-retest analysis, considering follow-up loss rate of $15 \%$. These 35 patients were included in the original cohort of 116 women.

The inclusion criteria for the control group $(\mathrm{n}=58)$ were: 1$)$ an absence of major chronic and acute disease, 2) no history of treatment for lower urinary tract symptoms, and 3) no subjective complaints of voiding symptoms. Exclusion criteria were being treated for urological conditions including stress urinary incontinence and urinary tract infection. In summary, asymptomatic subjects with no or mild voiding symptoms visiting the Health Promotion Center in SNUH for a routine health checkup were selected for the control group.

After receiving information about the purpose and nature of the study, all participants of $\mathrm{OAB}$ group and control group provided written informed consent. Clinical and demographic data were collected from all participants. The OAB group then completed questions for the face validity, Korean version of the $\mathrm{OAB}-\mathrm{q}$, a fully-validated Korean version of the KHQ, and Medical Outcomes Study SF-36 which is well-known as a typical type of generic non-disease specific questionnaire to assess HRQoL. The control group completed the OAB-q, KHQ, and SF-36. The permission for use of afore-mentioned questionnaires for this study was obtained from each copyright holder.

\section{Validity}

To assess face and content validity, questions were adopted from 
our previous study that validated the Korean version of the KHQ $[17,18]$. A descriptive analysis was performed for each question. The ability of the OAB-q to discriminate OAB patients from individuals in the control group was examined by comparing tertiles of the baseline OAB-q scores. Clinical indicators including KHQ and SF-36 scores were also compared between the two groups. Wilcoxon rank sums test was used to determine whether scores of the $\mathrm{OAB}$ patients were significantly different from those of the control group. Convergent validation involved comparing the OAB-q total score as well as the four subscale scores with appropriately related measures including the KHQ and SF-36 scores using Spearman's correlation coefficients.

\section{Reliability}

Internal consistency of the Korean OAB-q was assessed by calculating Cronbach's coefficient. After the first surveys were completed, the participants were offered the same questionnaire 2 weeks later to demonstrate reproducibility. We expected that the 2-week interval was a sufficient amount of time for respondents to forget their original answers but not long enough for any $\mathrm{OAB}$ symptoms to dramatically change. Test-retest reliability was assessed using the intra-class correlation coefficient, which is derived from an analysis of variance, and Spearman's correlation. Spearman's correlation coefficients were classified as small $(0.10)$, moderate $(0.30)$, or large $(0.50)$.

\section{Responsiveness}

Responsiveness is the ability of an instrument to detect small but important changes. The $\mathrm{OAB}$ group was given tolterodine SR (4 mg per day) or other comparable anticholinergic agents for 12 weeks to evaluate sensitivity of the OAB-q to symptom change. Patients completed the OAB-q before and after 12 weeks of treatment. Responsiveness was analyzed by calculating the differences in the Korean OAB-q scores before and after treatment using Wilcoxon signed rank test. Effect sizes of the OAB$\mathrm{q}$ were calculated by dividing the difference in mean scores from baseline to week 12 by the standard deviation of the baseline scores. Effect size was classified as small (0.20), moderate (0.50), or large (0.80). The standardized response mean was calculated by dividing the difference in mean scores before and after treatment by the standard deviation of this difference.

\section{Statistical Analysis}

All statistical analyses were independently performed using SAS Ver. 18.0 (SAS Institute Inc., Cary, NC, USA) by biostatisticians
(SOK, MSL). Patient characteristics were expressed as mean \pm $\mathrm{SD}$ for continuous variables and as $\mathrm{N}$ and percentages for categorical variables. Any questionnaires with missing items were excluded from the analysis. If $\leq 50 \%$ of the scale items were missing in the subscale analysis, the scale was retained and the mean scale score of the items present were used to impute a score for the missing items. If $>50 \%$ of the items was missing, no scale scores were calculated and were considered to be missing [7]. If subscales score were missing, the HRQoL total score was not calculated.

\section{RESULTS}

\section{Readability and Acceptability}

Demographic and clinical characteristics of the patients are summarized in Table 1. The mean age was $62.7( \pm 10.2, \mathrm{SD})$ years. Assessment of face validity showed that the Korean version of the OAB-q was acceptable (Table 2). $81.0 \%$ of the patients said that time taken to complete answering the questionnaire were within 20 minutes and $84.4 \%$ stated that each question was simple and easy to understand. The participants thought that most items of the OAB-q were relevant, each question was clearly worded and easily understood, and the format of the questionnaire was acceptable.

\section{Validity}

\section{Discriminant validity}

Significant differences were noted between the scores for the control and OAB groups. All OAB-q and OAB-q SF subscales showed sufficient discriminate validity $(\mathrm{P}<0.001)$ (Table 3$)$. There were also significant differences between the two groups in all KHQ subscales. Significant differences were also consistently noted between the control and OAB groups in most SF36 domains $(\mathrm{P}<0.05)$.

\section{Convergent validity}

Compared to OAB-related measures (Table 4), the OAB-q subscales moderately correlated with the KHQ subscales $(\mathrm{P}<0.05)$. Convergent validity was acceptable with high correlation coefficients among conceptually-related domains. Domains related to limitations of daily life including physical limitations, social limitations, and sleep/energy in the KHQ showed high correlations with the OAB-q domains. However, correlations between the OAB-q scores and SF-36 of the OAB patients were relatively weak compared to other inter-domain correlations (e.g., in 
Table 1. Demographics of the 58 overactive bladder patients

\begin{tabular}{|c|c|c|}
\hline Item & & No. $(\%)$ \\
\hline \multirow[t]{6}{*}{ Age (yr) } & $30-39$ & $1(1.7)$ \\
\hline & $40-49$ & $7(12.0)$ \\
\hline & $50-59$ & $15(25.8)$ \\
\hline & $60-69$ & $24(41.3)$ \\
\hline & $70-79$ & $7(12.0)$ \\
\hline & $80-$ & $4(6.9)$ \\
\hline \multirow[t]{6}{*}{ Residence } & Seoul & 37 (64.9) \\
\hline & Busan & $1(1.7)$ \\
\hline & Incheon & $3(5.2)$ \\
\hline & Ulsan & $1(1.7)$ \\
\hline & Gyeonggi-do province & $13(22.8)$ \\
\hline & Jeollanam-do province & $2(3.5)$ \\
\hline \multirow{2}{*}{$\begin{array}{l}\text { History of genitourinary } \\
\text { surgery }\end{array}$} & Yes & $6(10.3)$ \\
\hline & No & $52(89.6)$ \\
\hline \multirow[t]{4}{*}{ History of surgery ${ }^{a}$} & Hysterectomy & $16(27.5)$ \\
\hline & Brain or spinal surgery & $3(5.1)$ \\
\hline & Others & $18(31.0)$ \\
\hline & No & $21(36.2)$ \\
\hline \multirow[t]{5}{*}{ History of disease $\mathrm{a}^{\mathrm{a}}$} & Stroke & $1(1.7)$ \\
\hline & Diabetes mellitus & $14(24.5)$ \\
\hline & Brain or spinal injury & $1(1.7)$ \\
\hline & Brain or spinal disease & $1(1.7)$ \\
\hline & No & $40(70.1)$ \\
\hline \multirow[t]{3}{*}{ Marital status } & $\begin{array}{l}\text { Married and living with } \\
\text { spouse }\end{array}$ & $44(78.5)$ \\
\hline & Widowed & $8(14.2)$ \\
\hline & Divorced & $4(7.1)$ \\
\hline \multirow[t]{5}{*}{ Occupation } & Agriculture & $1(1.7)$ \\
\hline & Service, merchant & $3(5.1)$ \\
\hline & Professional, management & $1(1.7)$ \\
\hline & Housewife & $46(79.3)$ \\
\hline & No & $7(12.0)$ \\
\hline \multirow[t]{4}{*}{ Level of education } & Elementary school & $15(25.8)$ \\
\hline & Middle school & $16(27.5)$ \\
\hline & High school & $16(27.5)$ \\
\hline & College or higher & $11(18.9)$ \\
\hline \multirow{5}{*}{$\begin{array}{l}\text { Monthly income (Korean } \\
\text { won) }\end{array}$} & Less than 1.0 million & $17(29.3)$ \\
\hline & 1.0-1.9 million & $9(15.5)$ \\
\hline & 2.0-2.9 million & $14(24.1)$ \\
\hline & Over 3.0 million & $13(22.4)$ \\
\hline & No response & $5(8.6)$ \\
\hline
\end{tabular}

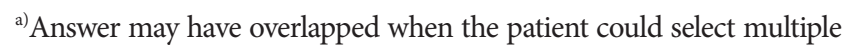
responses.
Table 2. Face validity of the overactive bladder questionnaire $(\mathrm{n}=58)$

\begin{tabular}{lc}
\hline Item & No. $(\%)$ \\
\hline Time taken to complete the questionnaire (min) & \\
7 & $1(1.7)$ \\
10 & $1(1.7)$ \\
15 & $9(15.5)$ \\
20 & $47(81.0)$ \\
Is each question simple and easy to understand ? & \\
Not at all & $3(5.1)$ \\
A little & $6(10.3)$ \\
Moderately & $25(43.1)$ \\
Quite a bit & $20(34.4)$ \\
Extremely & $4(6.9)$ \\
Is questionnaire relevant to your condition? & \\
Not at all & $1(1.7)$ \\
A little & $4(6.9)$ \\
Moderately & $23(39.6)$ \\
Quite a bit & $23(39.6)$ \\
Extremely & $7(12.0)$ \\
Is each question clear and easy to understand? & \\
Not at all & $23(39.6)$ \\
A little & \\
Moderately & $1(1.7)$ \\
Quite a bit & $4(6.9)$ \\
Extremely & $25(43.1)$ \\
Is the format of questionnaire easy to understand ? & \\
Not at all & \\
A little & \\
Moderately & \\
Quite a bit & \\
\hline
\end{tabular}

OAB-q HRQoL total, 0.010 with SF-36 mental health, 0.065 with SF-36 pain). These results indicate low discriminant validity with relatively weak correlation among conceptually unrelated domains.

\section{Reliability Internal consistency}

Cronbach's alpha coefficients $(>0.82)$ indicated excellent internal consistency (Table 5). The OAB-q SF HRQoL was found to have high internal consistency according to the Cronbach's al- 
Table 3. Discriminant validity

\begin{tabular}{|c|c|c|c|c|}
\hline $\begin{array}{l}\text { Question- } \\
\text { naire }\end{array}$ & Domain & $\begin{array}{l}\text { Control } \\
(\mathrm{n}=58)\end{array}$ & $\begin{array}{l}\text { Patient } \\
\text { group } \\
(\mathrm{n}=58)\end{array}$ & P-value \\
\hline \multirow[t]{6}{*}{ OAB-q } & Symptom severity & $12.2 \pm 12.0$ & $46.9 \pm 20.3$ & $<0.001$ \\
\hline & Coping & $91.4 \pm 12.2$ & $59.7 \pm 25.1$ & $<0.001$ \\
\hline & Concern & $92.7 \pm 8.1$ & $66.6 \pm 22.2$ & $<0.001$ \\
\hline & Sleep & $86.5 \pm 13.1$ & $56.4 \pm 26.4$ & $<0.001$ \\
\hline & Social & $95.3 \pm 10.2$ & $76.4 \pm 25.6$ & $<0.001$ \\
\hline & HRQoL total & $91.6 \pm 9.1$ & $64.3 \pm 21.8$ & $<0.001$ \\
\hline \multirow[t]{2}{*}{ OAB-q SF } & Symptom severity & $12.6 \pm 12.5$ & $45.1 \pm 21.3$ & $<0.001$ \\
\hline & HRQoL total & $91.5 \pm 9.5$ & $63.0 \pm 22.2$ & $<0.001$ \\
\hline \multirow[t]{9}{*}{ KHQ } & General health & $49.1 \pm 20.9$ & $65.5 \pm 23.3$ & $<0.001$ \\
\hline & Impact on life & $39.6 \pm 30.8$ & $71.8 \pm 24.8$ & $<0.001$ \\
\hline & Role limitations & $10.9 \pm 18.3$ & $57.1 \pm 32.7$ & $<0.001$ \\
\hline & Physical limitations & $15.5 \pm 17.6$ & $59.6 \pm 31.0$ & $<0.001$ \\
\hline & Social limitations & $3.4 \pm 11.0$ & $35.1 \pm 34.7$ & $<0.001$ \\
\hline & $\begin{array}{l}\text { Personal relation- } \\
\text { ships }\end{array}$ & $10.4 \pm 18.2$ & $31.7 \pm 31.3$ & 0.003 \\
\hline & Emotions & $8.6 \pm 16.1$ & $50.0 \pm 32.3$ & $<0.001$ \\
\hline & Sleep/energy & $13.2 \pm 15.8$ & $46.5 \pm 29.9$ & $<0.001$ \\
\hline & Severity measures & $10.3 \pm 10.0$ & $34.4 \pm 28.2$ & $<0.001$ \\
\hline \multirow[t]{8}{*}{ SF-36 } & Physical functioning & $76.3 \pm 21.2$ & $55.5 \pm 30.0$ & $<0.001$ \\
\hline & Role-physical & $77.2 \pm 22.9$ & $60.1 \pm 31.2$ & 0.004 \\
\hline & Pain & $69.1 \pm 28.5$ & $58.3 \pm 28.7$ & 0.041 \\
\hline & General health & $49.6 \pm 19.3$ & $38.7 \pm 20.6$ & 0.006 \\
\hline & Vitality & $48.7 \pm 21.7$ & $40.2 \pm 22.9$ & 0.058 \\
\hline & Social functioning & $80.3 \pm 20.9$ & $71.3 \pm 24.2$ & 0.041 \\
\hline & Role-emotional & $77.8 \pm 24.7$ & $63.3 \pm 31.1$ & 0.014 \\
\hline & Mental health & $64.5 \pm 20.8$ & $58.0 \pm 22.3$ & 0.204 \\
\hline
\end{tabular}

Values are presented as the mean \pm standard deviation and analyzed using Wilcoxon rank-sums test.

OAB-q, overactive bladder questionnaire; HRQoL, health-related quality of life; OAB-q SF, overactive bladder questionnaire short form; KHQ, King's health questionnaire; SF-36, short-form 36.

pha coefficient (0.90).

\section{Reproducibility}

Test-retest analysis showed that each item as well as subscale scores were reproducible (Table 6). Interclass correlation coefficients for domains of the OAB-q subscales and SF ranged from 0.55 to 0.77 ( $\mathrm{P}<0.001$ for all). Spearman's correlations for the OAB-q HRQoL (0.69) and OAB-q SF HRQoL indicated a strong association between participant responses during the first and second visit $(\mathrm{P}<0.001)$. Analysis of each $\mathrm{OAB}-\mathrm{q}$ item indicated that the responses between the two visits remained consistent.

\section{Responsiveness \\ Change in scores before and after treatment}

A total of $35 \mathrm{OAB}$ patients started anticholinergic medication and 27 patients were followed-up. The OAB-q scales, except those for the social and OAB-q SF, exhibited significant change $(\mathrm{P}<0.001)$ (Table 7). Treatment also led to significant changes in all KHQ scores except for ones associated with Personal Relationships $(\mathrm{P}<0.05)$.

\section{Effect size and standardized response mean}

Results indicating the effect size and response mean for the OAB-q scales from baseline to week 12 of treatment are shown in Table 7. The effect sizes of the OAB-q subscales from baseline to week 12 ranged from 0.57 to 1.48 . All subscales except the social subscale showed large effect sizes. Results for the standardized response mean were similar to those of the effect sizes.

\section{DISCUSSION}

$\mathrm{OAB}$ is defined by symptoms. For symptoms based on pathological conditions, HRQoL is considered to be a key factor for evaluating intervention effects. Therefore, critical quantification of a patient's symptoms is an absolute necessity for analyzing baseline symptomatic distress and assessing changes in distress and HRQoL in response to drug therapy and/or surgery. One of the most widely used questionnaires for patients with urinary incontinence is the KHQ. This questionnaire was translated into Korean and the linguistic accuracy was validated by our team [17]. Subsequent full-scale psychometric evaluation was also performed, proving that the KHQ is a valid and reliable tool for assessing female patients with stress urinary incontinence [18]. The KHQ is commonly used to assess urge incontinence. However, it was not developed to specifically examine conditions associated with $\mathrm{OAB}$. A more direct comparison between the $\mathrm{KHQ}$ and $\mathrm{OAB}-\mathrm{q}$ has not been performed although it is generally assumed that the OAB-q, which is a condition-specific questionnaire, is superior to more generic questionnaires.

Some Korean patients and physicians have reported that the original Korean version of the OAB-q (ver. 1.0) is difficult to understand. These individuals pointed out that some parts of the sentences were confusing because they were directly translated from English into Korean. Since the final validated version 
Table 4. Convergent validity of the OAB-q

\begin{tabular}{|c|c|c|c|c|c|c|c|c|c|}
\hline & \multirow[b]{2}{*}{ No. } & \multicolumn{8}{|c|}{ OAB-q } \\
\hline & & $\begin{array}{l}\text { Symptom } \\
\text { severity }\end{array}$ & Coping & Concern & Sleep & Social & HRQoL total & $\begin{array}{c}\text { Short form } \\
\text { symptom } \\
\text { severity }\end{array}$ & $\begin{array}{l}\text { Short form } \\
\text { HRQoL total }\end{array}$ \\
\hline \multicolumn{10}{|l|}{ KHQ } \\
\hline General health & 58 & $0.226^{\mathrm{a})}$ & -0.288 & -0.303 & -0.439 & -0.366 & -0.410 & $0.238^{\mathrm{a})}$ & -0.347 \\
\hline Impact on Life & 58 & 0.628 & -0.603 & -0.648 & -0.508 & -0.400 & -0.646 & 0.590 & -0.656 \\
\hline Role limitations & 58 & 0.649 & -0.650 & -0.498 & -0.533 & -0.543 & -0.679 & 0.609 & -0.670 \\
\hline Physical limitations & 57 & 0.611 & -0.628 & -0.614 & -0.638 & -0.509 & -0.723 & 0.565 & -0.738 \\
\hline Social limitations & 58 & 0.511 & -0.605 & -0.650 & -0.617 & -0.604 & -0.741 & 0.520 & -0.740 \\
\hline Personal relationships & 41 & $0.250^{\mathrm{a})}$ & $-0.190^{\mathrm{a})}$ & -0.363 & $-0.198^{\text {a) }}$ & -0.405 & -0.314 & $0.249^{\mathrm{a})}$ & $-0.272^{\mathrm{a})}$ \\
\hline Emotions & 58 & 0.404 & -0.475 & -0.606 & -0.338 & -0.479 & -0.554 & 0.368 & -0.552 \\
\hline Sleep/energy & 58 & 0.634 & -0.604 & -0.655 & -0.807 & -0.445 & -0.721 & 0.647 & -0.743 \\
\hline Severity measures & 58 & 0.367 & -0.476 & -0.499 & -0.349 & -0.442 & -0.543 & 0.392 & -0.520 \\
\hline \multicolumn{10}{|l|}{ SF-36 } \\
\hline Physical functioning & 58 & -0.261 & 0.322 & 0.304 & 0.324 & $0.243^{\mathrm{a})}$ & 0.371 & -0.298 & 0.325 \\
\hline Role-physical & 58 & $-0.159^{\mathrm{a})}$ & 0.356 & 0.418 & 0.340 & 0.267 & 0.409 & $-0.216^{\mathrm{a})}$ & 0.388 \\
\hline Pain & 58 & $-0.100^{\mathrm{a})}$ & $0.124^{\mathrm{a})}$ & $0.051^{\mathrm{a})}$ & $0.239^{\mathrm{a})}$ & $0.079^{\mathrm{a})}$ & $0.144^{\mathrm{a})}$ & $-0.065^{a)}$ & $0.095^{\mathrm{a})}$ \\
\hline General health & 58 & $-0.153^{\mathrm{a})}$ & $0.115^{\mathrm{a})}$ & $0.217^{\mathrm{a})}$ & 0.289 & $0.162^{a)}$ & $0.235^{\mathrm{a})}$ & $-0.218^{\text {a) }}$ & $0.193^{\mathrm{a})}$ \\
\hline Vitality & 57 & $-0.153^{\mathrm{a})}$ & $0.180^{\mathrm{a})}$ & $0.239^{\mathrm{a})}$ & 0.324 & $0.161^{\mathrm{a})}$ & $0.253^{\mathrm{a})}$ & $-0.151^{\text {a) }}$ & $0.238^{\mathrm{a})}$ \\
\hline Social functioning & 58 & $-0.147^{a)}$ & $0.218^{\mathrm{a})}$ & 0.282 & $0.217^{\mathrm{a})}$ & 0.326 & 0.319 & $-0.190^{\mathrm{a})}$ & 0.285 \\
\hline Role-emotional & 58 & $-0.210^{\text {a) }}$ & 0.330 & 0.295 & 0.272 & $0.152^{\mathrm{a})}$ & 0.343 & $-0.248^{\mathrm{a})}$ & 0.331 \\
\hline Mental health & 57 & $0.006^{\mathrm{a})}$ & $-0.050^{\mathrm{a})}$ & $0.145^{\mathrm{a})}$ & $0.134^{\mathrm{a})}$ & $0.114^{\mathrm{a})}$ & $0.054^{\mathrm{a})}$ & $-0.010^{\mathrm{a})}$ & $0.006^{\mathrm{a}}$ \\
\hline
\end{tabular}

OAB-q, overactive bladder questionnaire; HRQoL, health-related quality of life; KHQ, King's health questionnaire; SF-36, short-form 36. a) Spearman's correlations coefficients is not significant at $\alpha=0.05$.

Table 5. Internal consistency of the OAB-q at the first visit $(\mathrm{n}=58)$

\begin{tabular}{llcc}
\hline Questionnaire & \multicolumn{1}{c}{ Domain } & No. of items & Cronbach's $\alpha$ \\
\hline OAB-q & Symptom severity & 8 & 0.82 \\
& Coping & 8 & 0.87 \\
& Concern & 7 & 0.87 \\
& Sleep & 5 & 0.86 \\
& Social & 5 & 0.86 \\
& HRQoL total & 33 & 0.95 \\
OAB-q SF & Symptom severity & 6 & 0.77 \\
& HRQoL total & 13 & 0.90 \\
\hline
\end{tabular}

OAB-q, overactive bladder questionnaire; HRQoL, health-related quality of life; OAB-q SF, overactive bladder questionnaire short form.

has may be widely used by both Korean patients and physicians, we felt that a revision was necessary. Prior to starting the psy- chometric validation, the Korean OAB-q underwent another linguistic review by our research team including back translation, forward translation, reconciliation, and debriefing patient interview. Thorough review of the new version was performed and expert opinion of the revised version was obtained from leading urologists who were involved in creating the first version of the Korean OAB-q. Finally, 11 minor revisions were made in the final Korean version 2.0 based on a comparison to the original version (the process was completed on June 26, 2007). The revised version (2.0) of the Korean OAB-q was then psychometrically validated.

In the present study, full-scale psychometric properties including content/face validity, discriminant validity, convergent validity, internal consistency, test-retest analysis, and responsiveness of the Korean OAB-q were evaluated in a Korean population. The OAB-q and OAB-q SF was validated using two distinct groups, control and patients. The results varied accord- 
Table 6. Reproducibility of the OAB-q data

\begin{tabular}{|c|c|c|c|}
\hline $\begin{array}{l}\text { Question- } \\
\text { naire }\end{array}$ & Domain or item & $\begin{array}{c}\text { Intra-class correlation } \\
\text { coefficient }\end{array}$ & $\begin{array}{l}\text { Spearman's } \\
\text { correlations }\end{array}$ \\
\hline \multirow[t]{6}{*}{$\mathrm{OAB}-\mathrm{q}$} & Symptom severity & $0.67(0.445,0.820)$ & $0.65^{\mathrm{b})}$ \\
\hline & Coping & $0.66(0.434,0.816)$ & $0.63^{\mathrm{b})}$ \\
\hline & Concern & $0.61(0.360,0.784)$ & $0.60^{\mathrm{b})}$ \\
\hline & Sleep & $0.77(0.607,0.881)$ & $0.78^{\mathrm{b})}$ \\
\hline & Social & $0.55(0.272,0.743)$ & $0.59^{\mathrm{b})}$ \\
\hline & HRQoL total & $0.69(0.471,0.831)$ & $0.69^{\mathrm{b})}$ \\
\hline \multirow[t]{35}{*}{ OAB-q SF } & Symptom severity & $0.67(0.452,0.823)$ & $0.66^{\mathrm{b})}$ \\
\hline & HRQoL total & $0.71(0.511,0.846)$ & $0.73^{\mathrm{b})}$ \\
\hline & 1 & $0.49(0.200,0.707)$ & $0.47^{\mathrm{a})}$ \\
\hline & 2 & $0.42(0.109,0.657)$ & $0.35^{\mathrm{a})}$ \\
\hline & 3 & $0.44(0.143,0.676)$ & $0.40^{\mathrm{a})}$ \\
\hline & 4 & $0.52(0.245,0.730)$ & $0.55^{\mathrm{b})}$ \\
\hline & 5 & $0.75(0.568,0.867)$ & $0.77^{\mathrm{b})}$ \\
\hline & 6 & $0.85(0.728,0.922)$ & $0.84^{\mathrm{b})}$ \\
\hline & 7 & $0.36(0.040,0.616)$ & $0.37^{\mathrm{a})}$ \\
\hline & 8 & $0.50(0.215,0.715)$ & $0.51^{\mathrm{a})}$ \\
\hline & 9 & $0.46(0.163,0.687)$ & $0.40^{\mathrm{a})}$ \\
\hline & 10 & $0.51(0.228,0.721)$ & $0.50^{\mathrm{a})}$ \\
\hline & 11 & $0.38(0.068,0.633)$ & $0.35^{\mathrm{a})}$ \\
\hline & 12 & $0.52(0.237,0.726)$ & $0.51^{\mathrm{a})}$ \\
\hline & 13 & $0.54(0.262,0.738)$ & $0.54^{\mathrm{b})}$ \\
\hline & 14 & $0.30(-0.025,0.574)$ & 0.21 \\
\hline & 15 & $0.67(0.447,0.821)$ & $0.67^{\mathrm{b})}$ \\
\hline & 16 & $0.38(0.069,0.634)$ & $0.40^{\mathrm{a})}$ \\
\hline & 17 & $0.36(0.044,0.619)$ & $0.38^{\mathrm{a})}$ \\
\hline & 18 & $0.47(0.176,0.694)$ & $0.57^{\mathrm{b})}$ \\
\hline & 19 & $0.49(0.201,0.708)$ & $0.52^{\mathrm{a})}$ \\
\hline & 20 & $0.65(0.413,0.807)$ & $0.68^{\mathrm{b})}$ \\
\hline & 21 & $0.57(0.301,0.757)$ & $0.52^{\mathrm{a})}$ \\
\hline & 22 & $0.58(0.315,0.763)$ & $0.56^{\mathrm{b})}$ \\
\hline & 23 & $0.73(0.542,0.858)$ & $0.62^{\mathrm{b})}$ \\
\hline & 24 & $0.85(0.733,0.924)$ & $0.86^{\mathrm{b})}$ \\
\hline & 25 & $0.35(0.028,0.609)$ & $0.56^{\mathrm{b})}$ \\
\hline & 26 & $0.59(0.336,0.773)$ & $0.58^{\mathrm{b})}$ \\
\hline & 27 & $0.28(-0.047,0.559)$ & $0.37^{\mathrm{a})}$ \\
\hline & 28 & $0.60(0.348,0.778)$ & $0.72^{\mathrm{b})}$ \\
\hline & 29 & $0.19(-0.143,0.489)$ & $0.63^{\mathrm{b})}$ \\
\hline & 30 & $0.65(0.413,0.807)$ & $0.67^{\mathrm{b})}$ \\
\hline & 31 & $0.15(-0.185,0.456)$ & 0.32 \\
\hline & 32 & $0.30(-0.026,0.574)$ & 0.32 \\
\hline & 33 & $0.64(0.410,0.805)$ & $0.65^{\mathrm{b})}$ \\
\hline
\end{tabular}

Differences in scores from the first and second visits $(n=35)$.

OAB-q, overactive bladder questionnaire; HRQoL, health-related quality of life; OAB-q SF, overactive bladder questionnaire short form.

${ }^{\text {a) }} \mathrm{P}<0.05$. ${ }^{\text {b) }} \mathrm{P}<0.001$. ing to these two groups, thus providing evidence of discriminant validity. There were also significant differences in the KHQ subscales except for the one that assessed personal relationships.

The SF-36 has been used extensively as an indicator of HRQoL, and its reliability and validity are well-documented [19]. However, our convergent validity study showed that correlations between the OAB-q scores and SF-36 in OAB patients were relatively weak. This might be because SF-36 is a generic questionnaire rather than a disease-specific one. Our previous study demonstrated that a generic QoL questionnaire is not a sensitive tool for measuring QoL in patients with urinary incontinence compared to more condition-specific [20]. Our test-retest analysis showed that the scores for each item and subscales were highly reproducible. Correlation analyses revealed a strong association between the $\mathrm{OAB}-\mathrm{q}$ scores recorded during the first and second visits. Cronbach's alpha coefficients also indicated excellent internal consistency. The usefulness of measuring outcomes based on self-reporting methods depends not only on the validity and reliability of the technique, but also on the ability to detect treatment-related changes over time. The effect size and standardized response mean from baseline to week 12 of treatment observed in this study showed that the OAB-q is a very sensitive tool for detecting relatively small subjective symptomatic changes that occurred between two visits.

A potential limitation of this study exists as all our subjects were female. There still lies a need to validate the Korean version of the OAB-q in the male population in the future, given that the $O A B$ affects both sexes. In addition we would also like to validate $\mathrm{OAB}$ patients of neurologic disease with coming revisions to our study. There is a growing need for fully validated $\mathrm{OAB}$ questionnaires in various languages for multinational clinical trials. Our results showed that full validation and crosscultural adaptation of the non-English version of the OAB-q has been done successfully. This study showed the Korean OAB$\mathrm{q}$ is associated with good psychometric properties in OAB subjects and demonstrated the usefulness of the Korean version of the OAB-q, an essential tool that can be utilized for international clinical trials and various clinical studies on $\mathrm{OAB}$.

In conclusion, the Korean version of the OAB-q is a valid and reliable instrument to measure outcomes in Korean patients with OAB.

\section{CONFLICT OF INTEREST}

No potential conflict of interest relevant to this article was re- 
Table 7. Changes in scores before and after treatment, effect size and standardized response mean for the OAB-q scales

\begin{tabular}{lllrrrrc}
\hline & No. & Mean & SD & P-value & Effect size & $\begin{array}{c}\text { Standardized } \\
\text { response mean }\end{array}$ \\
\hline$\Delta$ OAB-q $^{\text {a) }}$ & Symptom severity & 27 & -24.8 & 16.0 & $<0.001$ & -1.48 & -1.55 \\
& Coping & 27 & 19.3 & 20.3 & $<0.001$ & 0.91 & 0.95 \\
& Concern & 27 & 14.7 & 23.0 & 0.001 & 0.86 & 0.64 \\
& Sleep & 27 & 17.0 & 23.3 & $<0.001$ & 0.88 & 0.73 \\
& Social & 27 & 7.4 & 20.4 & 0.059 & 0.57 & 0.36 \\
& HRQoL total & 27 & 15.2 & 19.5 & $<0.001$ & 0.89 & 0.78 \\
\multirow{5}{*}{ OAB-q SF $^{\text {a) }}$} & Symptom severity & 27 & -21.8 & 16.9 & $<0.001$ & -1.24 & -1.29 \\
& HRQoL total & 27 & 16.6 & 18.8 & $<0.001$ & 1.04 & 0.88 \\
\hline
\end{tabular}

OAB-q, overactive bladder questionnaire; HRQoL, health-related quality of life; OAB-q SF, overactive bladder questionnaire short form. ${ }^{\text {a) }}$ Differences in scores from the first and second visits, Wilcoxon signed rank test.

ported.

\section{ACKNOWLEDGEMENTS}

This research was funded by Pfizer Korea Ltd.

\section{REFERENCES}

1. Abrams P, Cardozo L, Fall M, Griffiths D, Rosier P, Ulmsten U, et al. The standardisation of terminology of lower urinary tract function: report from the Standardisation Sub-committee of the International Continence Society. Neurourol Urodyn 2002;21:167-78.

2. Milsom I, Abrams P, Cardozo L, Roberts RG, Thuroff J, Wein AJ. How widespread are the symptoms of an overactive bladder and how are they managed? A population-based prevalence study. BJU Int 2001;87:760-6.

3. Stewart WF, Van Rooyen JB, Cundiff GW, Abrams P, Herzog AR, Corey R, et al. Prevalence and burden of overactive bladder in the United States. World J Urol 2003;20:327-36.

4. Hu TW, Wagner TH, Bentkover JD, LeBlanc K, Piancentini A, Stewart WF, et al. Estimated economic costs of overactive bladder in the United States. Urology 2003;61:1123-8.

5. Jackson $\mathrm{S}$. The patient with an overactive bladder--symptoms and quality-of-life issues. Urology 1997;50(6A Suppl):18-22.

6. Liberman JN, Hunt TL, Stewart WF, Wein A, Zhou Z, Herzog AR, et al. Health-related quality of life among adults with symptoms of overactive bladder: results from a U.S. community-based survey. Urology 2001;57:1044-50.

7. Coyne K, Revicki D, Hunt T, Corey R, Stewart W, Bentkover J, et al. Psychometric validation of an overactive bladder symptom and health-related quality of life questionnaire: the OAB-q. Qual Life Res 2002;11:563-74.

8. Yoo ES, Kim BS, Kim DY, Oh SJ, Kim JC. The impact of overactive bladder on health-related quality of life, sexual life and psychological health in Korea. Int Neurourol J 2011;15:143-51.

9. Lubeck DP, Prebil LA, Peeples P, Brown JS. A health related quality of life measure for use in patients with urge urinary incontinence: a validation study. Qual Life Res 1999;8:337-44.

10. Reese PR, Pleil AM, Okano GJ, Kelleher CJ. Multinational study of reliability and validity of the King's Health Questionnaire in patients with overactive bladder. Qual Life Res 2003;12:427-42.

11. Matza LS, Thompson CL, Krasnow J, Brewster-Jordan J, Zyczynski T, Coyne KS. Test-retest reliability of four questionnaires for patients with overactive bladder: the overactive bladder questionnaire (OABq), patient perception of bladder condition (PPBC), urgency questionnaire (UQ), and the primary $\mathrm{OAB}$ symptom questionnaire (POSQ). Neurourol Urodyn 2005;24:215-25.

12. Coyne KS, Matza LS, Thompson CL. The responsiveness of the Overactive Bladder Questionnaire (OAB-q). Qual Life Res 2005; 14:849-55.

13. Homma Y, Yoshida M, Seki N, Yokoyama O, Kakizaki H, Gotoh M, et al. Symptom assessment tool for overactive bladder syndrome-overactive bladder symptom score. Urology 2006;68:318-23.

14. Gotoh M, Homma Y, Yokoyama O, Nishizawa O. Responsiveness and minimal clinically important change in overactive bladder symptom score. Urology 2011;78:768-73.

15. Acquadro C, Kopp Z, Coyne KS, Corcos J, Tubaro A, Choo MS, et al. Translating overactive bladder questionnaires in 14 languages. Urology 2006;67:536-40.

16. Coyne KS, Margolis MK, Thompson C, Kopp Z. Psychometric 
equivalence of the OAB-q in Danish, German, Polish, Swedish, and Turkish. Value Health 2008;11:1096-101.

17. Oh SJ, Park HG, Paick SH, Park WH, Choo MS. Translation and linguistic validation of Korean version of the King's health questionnaire instrument. Korean J Urol 2005;46:438-50.

18. Oh SJ, Choo MS, Kim HS, Kim JC, Lee JG, Yun JM, et al. Psychometric Properties of the Korean version of the King's health questionnaire in women with stress urinary incontinence. J Korean
Continence Soc 2005;9:115-23.

19. Brazier JE, Harper R, Jones NM, O'Cathain A, Thomas KJ, Usherwood T, et al. Validating the SF-36 health survey questionnaire: new outcome measure for primary care. BMJ 1992;305:160-4.

20. Oh SJ, Ku JH. Does condition-specific quality of life correlate with generic health-related quality of life and objective incontinence severity in women with stress urinary incontinence? Neurourol Urodyn 2006;25:324-9. 